\section{Endoscopic removal of a nasogastric tube accidentally ligated to the duodenum after open abdominal surgery}

A 61-year-old man underwent open abdominal surgery for primary repair of a duodenal perforation. Preoperatively, a nasogastric tube had been inserted into the stomach for decompression. An attempt was made to remove the tube 6 days postoperatively but this was not possible because of marked resistance. Upper gastrointestinal endoscopy revealed that the nasogastric tube and granulation tissue were intertwined with a 3-0 Vicryl suture at the second portion of the duodenum ( $\boldsymbol{Q}$ Fig. 1 a).

A rat-tooth forceps and snare were used to try to sever the suture; however, the tube was not extirpated. Next, an endoscopic loop cutter (Olympus Medical Systems Corp., Aomori, Japan) was inserted into the side hole of the endoscope and an attempt was made to cut the suture $(\bullet$ Fig. 1 b). This effort was unsuccessful. The loop cutter had to be pulled forcibly while holding the suture, which finally resulted in the stitch being severed. The nasogastric tube was then removed successfully without further complications (O Fig.1 c). At the 1-week follow-up, the patient exhibited no abnormalities.

Very few cases of a nasogastric tube unintentionally sutured to the gastrointestinal tract have been reported worldwide [15]. This is the first reported case of this happening in the duodenum. If resistance is felt when pulling on a nasogastric tube, the tube should be left intact and endoscopy should be performed to identify the cause, as vigorous attempts to extirpate the tube may result in perforation or severe bleeding.

When the tube is trapped in the anastomotic site, it is safe to perform endoscopic treatment 2 weeks postoperatively [1,3]. However, in our case, endoscopic treatment was performed early and additional force was applied to the loop cutter to cut the tube. Despite this, it was a safe procedure because the tube was trapped in a comparatively intact part of the duodenum. Endoscopic treatment was safe, less expensive, and more convenient. It should be considered a first choice for this complication.

\section{Endoscopy_UCTN_Code_CPL_1AH_2AJ}

\section{Competing interests: None}

\section{Su Young Kim', Jun-Won Chung', Jun-Young Yang ${ }^{2}$}

${ }^{1}$ Division of Gastroenterology, Department of Internal Medicine, Gachon University, Gil Medical Center, Incheon, South Korea

2 Department of Surgery, Gachon University, Gil Medical Center, Incheon, South Korea

\section{References}

1 Chen CN, Lee WJ, Cheng TJ et al. Endoscopic removal of nasogastric tube sutured unintentionally to gastrojejunostomy. Surg Laparosc Endosc 1997; 7: 359-360

2 Shaaban H, Armstrong C. Nasogastric tube accidentally stitched to the stomach during laparoscopic antireflux surgery. Endoscopy 2009; 41 (Suppl. 02): E61

3 Han HF, Perng CL, Hung HC et al. latrogenic entrapped nasogastric tube with endoscopic removal. J Clin Gastroenterol 1999; 29: $103-104$

4 Wilkinson MN, Jayaraman V, Watkins K et al. Newly developed flexible endoscopic scissors for removal of a nasogastric tube trapped within a gastrojejunal anastomotic staple line. Endoscopy 2011; 43 (Suppl. 02): E234-E235

5 Mahmood A, Joseph E, Robinson RB et al. The role of endoscopy in nasogastric tube removal following esophageal surgery: a case report. Int J Surg 2007; 5: $342-344$

\section{Bibliography}

Dol http://dx.doi.org/

10.1055/s-0041-111028

Endoscopy 2016; 48: E18

(c) Georg Thieme Verlag KG

Stuttgart · New York

ISSN 0013-726X

\section{Corresponding author \\ Jun-Won Chung, MD, PhD}

Division of Gastroenterology

Department of Internal Medicine

Gachon University

Gil Medical Center

21, Namdong-daero 774beon-gil

Namdong-gu

Incheon

Korea

Fax: 82-32-4603408

junwonchung@daum.net
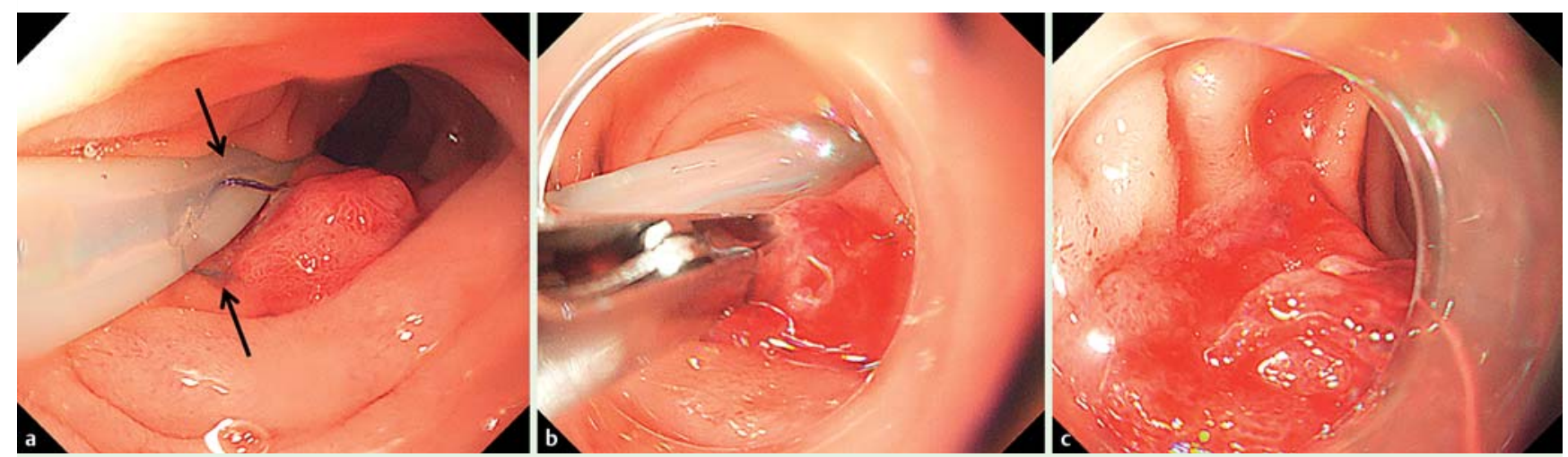

Fig. 1 Endoscopic views showing: a the nasogastric tube fixed by the 3-0 Vicryl suture (arrow) within the duodenum; $\mathbf{b}$ an endoscopic loop cutter being used in an attempt to extract the nasogastric tube; $\mathbf{c}$ the duodenum following removal of the nasogastric tube. 